\title{
Microgravity Smoldering Combustion of Flexible Polyurethane Foam with Central Ignition
}

\author{
Shuangfeng Wang $\cdot$ Xia Zhang
}

Received: 5 January 2007 / Accepted: 7 March 2008 / Published online: 23 April 2008

(C) Springer Science + Business Media B.V. 2008

\begin{abstract}
Smoldering constitutes a significant fire risk both in normal gravity and in microgravity. This space experiment has been conducted aboard the China Recoverable Satellite SJ-8 to investigate smoldering characteristics of flexible polyurethane foam with central ignition in a forced flow of oxidizer. This configuration resulted in a combination of opposed and forward flow smolder. The microgravity experiment is rather unique in that it was performed at constant pressure, and with a relatively high ambient oxygen concentration ( $35 \%$ by volume). The smoldering characteristics are inferred from measurements of temperature histories at several locations along the foam sample. Particularly important is the discovery that there is a transition from smoldering to flaming near the sample end in the opposed smoldering. This transition seems to be caused by strong acceleration of the smoldering reaction. The observed transition serves to initiate a vigorous forward-propagating oxidation reaction in the char left behind by the smoldering reaction. The secondary char oxidation reaction propagates through the sample and consumes most of the remaining char. In forward flow smoldering, the oxidizer depletion by the upstream opposed smolder prevents an exothermic oxidation reaction from being established in the foam until this preceding reaction is completed. Once fresh oxidizer flows in the sample, the existing conditions are sufficient for a self-sustained forward smoldering reaction to take place.
\end{abstract}

Keywords Smoldering combustion · Microgravity · Polyurethane foam

S. Wang $(\bowtie) \cdot X$. Zhang

National Microgravity Laboratory, Institute of Mechanics,

Chinese Academy of Sciences,

Beijing 100080, China

e-mail: sfwang@imech.ac.cn

\section{Introduction}

Smoldering is a non-flaming mode of combustion that occurs primarily in the interior of porous combustible materials (Ohlemiller 1986; Drysdale 1999). It is characterized by a weak, exothermic, and heterogeneous reaction with low characteristic temperatures $\left(\sim 300-400^{\circ} \mathrm{C}\right)$. Smoldering combustion has particular importance in the fire safety field because it is one of the most common forms of fire initiation. Furthermore, it provides a pathway to flaming fires through a sudden transition from smoldering to flaming, which can be initiated by heat sources too weak to cause a flaming combustion directly. Aboard a spacecraft, potential smolder fires have also been recognized as a significant hazard for some time. Should a fire occur in a space facility, there is high probability that it would originate from smoldering (Ross 2001). So far a few incidents of overheated and charred cables and electrical components have already been reported on NASA Space Shuttle flights (Friedman 1994).

One-dimensional smoldering is normally classified in two distinct groups: opposed and forward (Ohlemiller 1986), defined according to the relative directions in which the reaction zone and oxidizer propagate (as illustrated in Fig. 1). In forward smoldering, the reaction front propagates in the same direction as oxidizer flow, while in opposed (or reverse) smoldering the reaction front propagates opposing the oxidizer flow. Smoldering combustion is frequently oxygen limited, and thus a hot char with a significant amount of fuel content is left behind the propagating reaction front. For the smoldering to propagate, enough heat must be transferred from the exothermic reaction zone to the unreacted fuel by conduction, convection and radiation, heating the solid fuel and gaseous oxidizer to the smoldering reaction temperature. At the 
Fig. 1 Schematic of forward and opposed flow smolder

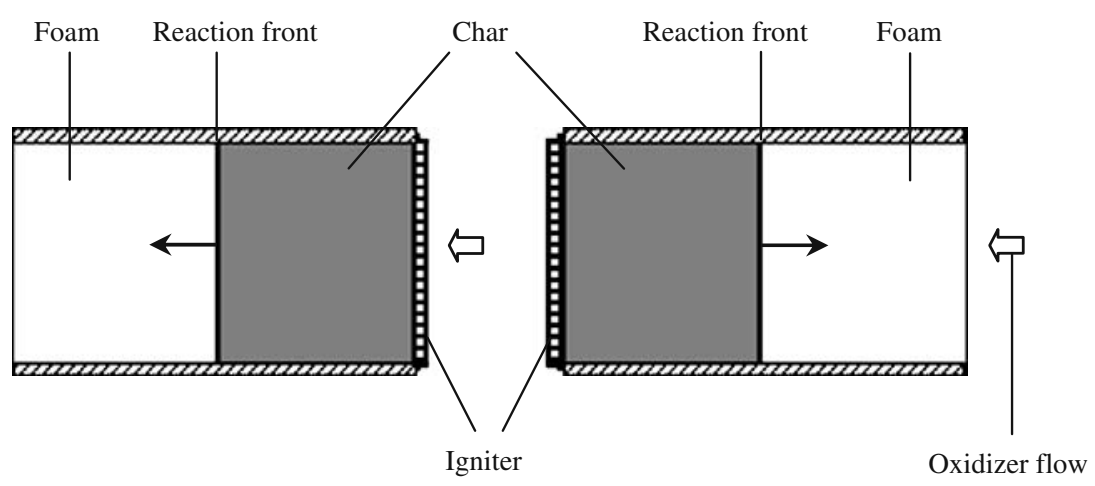

Forward flow smolder

Opposed flow smolder same time, sufficient oxygen must be transported to the reaction zone by diffusion and convection to support the reaction. These transport mechanisms determine the rate of smolder propagation and other characteristics of smoldering processes, i.e., ignition, extinction, and transition to flaming. Gravity level strongly influences smoldering process, at least due to effects of buoyant convection on the transport of heat and mass to and from the reaction zone. Since the smoldering reaction is very weak, and the flow velocity inside the solid fuel relatively low, the effect of buoyancy is generally important in the smoldering process, and can even play a dominant role in some circumstances (e.g., in a quiescent environment; Torero et al. 1993, 1994; Torero and Fernandez-Pello 1995). A smolder encountered in reduced gravity or microgravity (MG) is therefore expected to be different from that in normal gravity.

Although considerable experimental and theoretical work has been conducted on smoldering in normal gravity (Ohlemiller 1986; Drysdale 1999), there is less information available on smolder in MG. This could be mostly attributed to the scarce opportunities for getting the long period of MG required to accomplish smolder experiments (Torero et al. 1994; Cantwell and Fernandez-Pello 1990). Previous MG smoldering combustion experiments (Stocker et al. 1996; Walther et al. 1999; Bar-Ilan et al. 2002, 2004) were mainly focused on the pure opposed or forward flow smolder configurations, in which the smolder was initiated at one end of the sample and propagated toward another end. However, the combination of these two modes is practically important. In an actual fire, smoldering reaction is often initiated within the porous combustible material, and the subsequent smolder propagation takes place as a combination of opposed and forward modes. Moreover, as a convective environment of high oxygen concentration (up to $\sim 40 \%$ in some situations) can be expected in space facilities, the smolder process under such real conditions is of particular interest, with no information available to date.

The MG experiment presented here was conducted aboard the China Recoverable Satellite SJ-8 in September,
2006. To provide a rational basis for assessing the potential danger of smolder-initiated fires, this is an investigation of the mechanism of smoldering combustion in flexible polyurethane foam with central ignition. A mixture of $35 \% \mathrm{O}_{2}$ and $65 \% \mathrm{~N}_{2}$ by volume was used as oxidizer in the experiment, simulating the most dangerous smolder conditions in reality. The forced flow velocity of $3.1 \mathrm{~mm} / \mathrm{s}$ employed is representative of the convective environment in a space facility. Additionally, the MG smoldering experiment was conducted at a specified pressure (absolute value $\sim 97 \mathrm{kPa}$ ), while in previous experiments (Stocker et al. 1996; Walther et al. 1999; Bar-Ilan et al. 2002, 2004) ambient pressure in the test section underwent a substantial increase through the test. To the best of the authors' knowledge, this is the first MG smoldering experiment in which a combination of opposed and forward flow smolder has been investigated. It is also unique in that the ambient pressure was kept constant during the test and oxidizer with high oxygen concentration was used.

\section{Experimental Process}

Photographs of the flight hardware are shown in Fig. 2. The hardware includes two independent experimental modules (the results acquired on one module is reported here), each consisting of a test section with an embedded igniter, a flow system, and a temperature and pressure measurement system. The experimental modules are incorporated into the flight assembly which contains other components (e.g., the supporting electronics) of the hardware and appears as a two shelves structure. The flight assembly integrates into the instrument capsule of the Satellite SJ-8 of China. Its total weight is $50.5 \mathrm{~kg}$.

The test section is a cylindrical, aluminum duct of $150 \mathrm{~mm}$ inner diameter and $455 \mathrm{~mm}$ length, which can be divided into five sections as follows: a flow inlet diffuser, a $170 \mathrm{~mm}$ long fuel section that is attached to the diffuser and contains one fuel sample, an igniter section that contains the igniter, a $170 \mathrm{~mm}$ long fuel section that is attached to 
Fig. 2 Photographs of the flight hardware

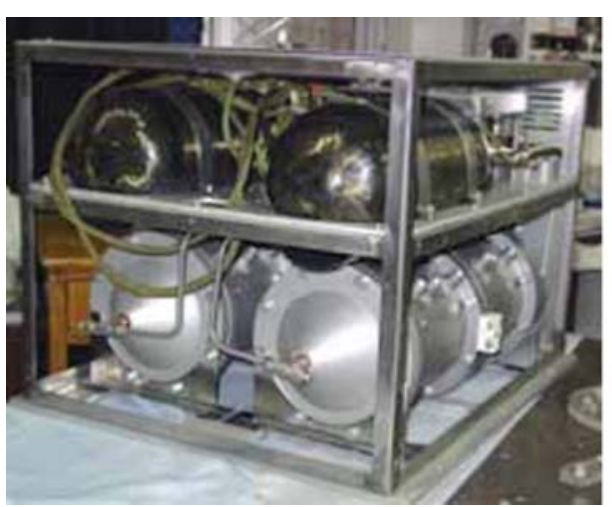

Flight assembly

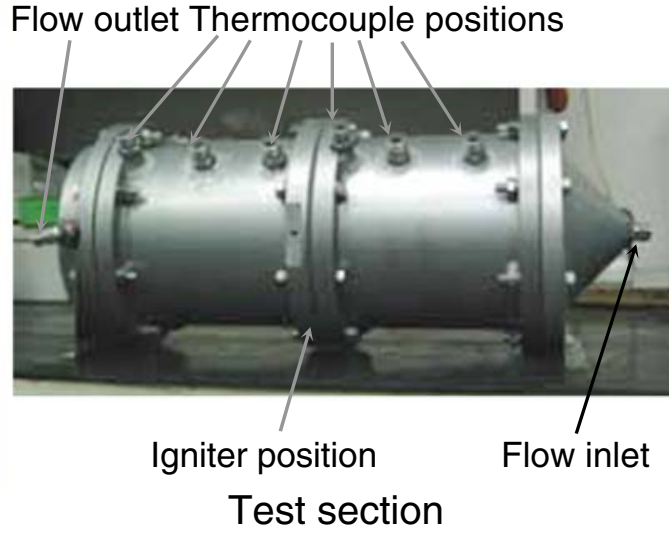

the downstream end of the igniter section and contains another fuel sample, and a gas outlet section. With the forced flow on, the smoldering propagation is an opposed type (opposing gas flow) upstream of the igniter, and a forward type (co-current gas flow) downstream. The fuel used in the experiment is open cell, white flexible polyurethane foam, with a $25 \mathrm{~kg} / \mathrm{m}^{3}$ density and 0.98 void fraction. This material is commonly used on Earth as well as aboard spacecrafts, and its properties are well known. To avoid preferential oxidizer flow between the foam and the container walls, foam samples with a diameter $10 \%$ larger than $150 \mathrm{~mm}$ is tightly fitted in the test section. The diametric size of the sample is also selected to reduce the effect of the cold walls on smoldering reaction, and to ensure a one-dimensional smolder propagation in a region of at least $70 \mathrm{~mm}$ in diameter at the core of the sample. The igniter is a resistively heated element consisting of a nichrome wire sandwiched between two thin honeycomb cordierite ceramic plates (of $8 \mathrm{~mm}$ thickness and $160 \mathrm{~mm}$ diameter, with 43 holes $/ \mathrm{cm}^{2}$ ) that provide rigidity to the igniter and heat the samples uniformly. The igniter is placed between the two fuel sections in good contact with the end surfaces of foam cylinders. Powered by $28 \mathrm{~V}$ lithium storage batteries, the igniter generates an ignition power of $110 \mathrm{~W}$ in the experiment.

The flow system serves to accomplish two functions: to provide a constant oxidizer flow to the test section (via an oxidizer supply subsystem) and to keep the ambient pressure in the test section (via a gas release subsystem). The oxidizer supply subsystem is connected to the flow inlet of the test section, and consists mainly of a 4.2-1 bottle charged with the oxidizer $\left(35 \% \mathrm{O}_{2} / 65 \% \mathrm{~N}_{2}\right)$ up to $10 \mathrm{MPa}$, magnetically latching solenoid valves to control the supply of oxidizer, and flow regulators to deliver the oxidizer flux at specific rates. Two pre-calibrated flow restrictors are included in the subsystem, one providing a flow velocity of $1.0 \mathrm{~mm} / \mathrm{s}$ in the test section, and another $3.1 \mathrm{~mm} / \mathrm{s}$. During the ignition period, the lower flow is used in order to reduce the effect of the ignition process on the forward smoldering.
The ignition flow is switched to the larger test flow via the solenoid valves after the foam smoldering initiation (ignition) has been performed. The gas release subsystem is connected to the gas outlet of the test section at one end and the pipelines in the satellite at the other end. Its central part is a pressure relief valve, that opens automatically when the upstream ambient pressure exceeds a specific value (absolute pressure $97 \mathrm{kPa}$ ), releasing excess gas from the test section. Via this valve, the whole test can be conducted at a constant pressure. The flow and pressure conditions are verified by pressure transducers at the bottle and test section respectively. The variation in flow through the test is negligible, and the variation in pressure is $\pm 5 \mathrm{kPa}$.

The temperature of the foams during smoldering combustion is measured by 12 type-K thermocouples, which are located at predetermined positions in the foams with their junctions placed along the fuel centerline. The thermocouples are evenly divided into two groups, one group (TO1-TO6) embedded in the opposed smoldering foam, and another (TF1-TF6) in the forward smoldering foam. Table 1 shows the distribution of the thermocouples in the fuel samples. During the experiment, the lower ignition oxidizer flow is initiated before the igniter being turned on. The power to the igniter is applied until the temperature of the foam at $10 \mathrm{~mm}$ downstream of the igniter (TF1) reached $340^{\circ} \mathrm{C}$, which is interpreted as an

Table 1 Distribution of the thermocouples in the foam samples

\begin{tabular}{lclll}
\hline \multicolumn{2}{l}{ Opposed smolder } & & \multicolumn{2}{l}{ Forward smolder } \\
\cline { 1 - 2 } \cline { 5 - 5 } $\begin{array}{l}\text { Thermocouple } \\
\text { no. }\end{array}$ & $\begin{array}{l}\text { Distance from } \\
\text { igniter }(\mathrm{mm})\end{array}$ & & $\begin{array}{l}\text { Thermocouple } \\
\text { no. }\end{array}$ & $\begin{array}{l}\text { Distance from } \\
\text { igniter }(\mathrm{mm})\end{array}$ \\
\hline TO1 & 15 & & TF1 & 10 \\
TO2 & 30 & & TF2 & 25 \\
TO3 & 60 & & TF3 & 55 \\
TO4 & 90 & & TF4 & 85 \\
TO5 & 120 & & TF5 & 115 \\
TO6 & 150 & & TF6 & 145 \\
\hline
\end{tabular}


indication that the smoldering initiation is accomplished. At that time, the igniter and ignition flow are turned off, and the oxidizer flow is changed to the larger test velocity. The temperature data are recorded at $0.5 \mathrm{~Hz}$, while the pressure data at $10 \mathrm{~Hz}$. Data recording continues for about $125 \mathrm{~min}$.

Apart from the smoldering experiment in MG, thermogravimetric analysis (TGA) of the polyurethane foam is performed with a Netzsch STA-409C analyzer to provide some information on the behavior of the foam material during its thermal decomposition. In Fig. 3, the TGA data are shown. It is observed that the decomposition of the foam occurs in two distinct stages with maximum decomposition rate temperatures of $\sim 330^{\circ} \mathrm{C}$ and $\sim 570^{\circ} \mathrm{C}$ when the sample is decomposed in air. When the sample is decomposed in $35 \% \mathrm{O}_{2} / 65 \% \mathrm{~N}_{2}$ atmosphere, these maximum decomposition rates temperatures are $\sim 310^{\circ} \mathrm{C}$ and $\sim 570^{\circ} \mathrm{C}$. The first stage corresponds to the decomposition of the foam while the second can be attributed to the oxidation of the char. The TGA measurements reveal that increasing the oxygen concentration moves the weight loss curves along the abscissa, implying that the thermal decomposition of the foam depends strongly on the oxygen concentration.

\section{Results and Discussion}

The characteristics of the smoldering process are obtained from the temperature histories in the foam samples. In the smoldering configuration treated here, the smoldering reaction upstream of the igniter (i.e. opposed smolder) occurs in a typical opposed flow smoldering configuration, and should be independent of the downstream one (forward smolder). On other hand, the forward smoldering experiences deep influences of the opposed smoldering process since its oxygen availability is dictated by the oxygen consumption in the latter. Such an influence is also borne

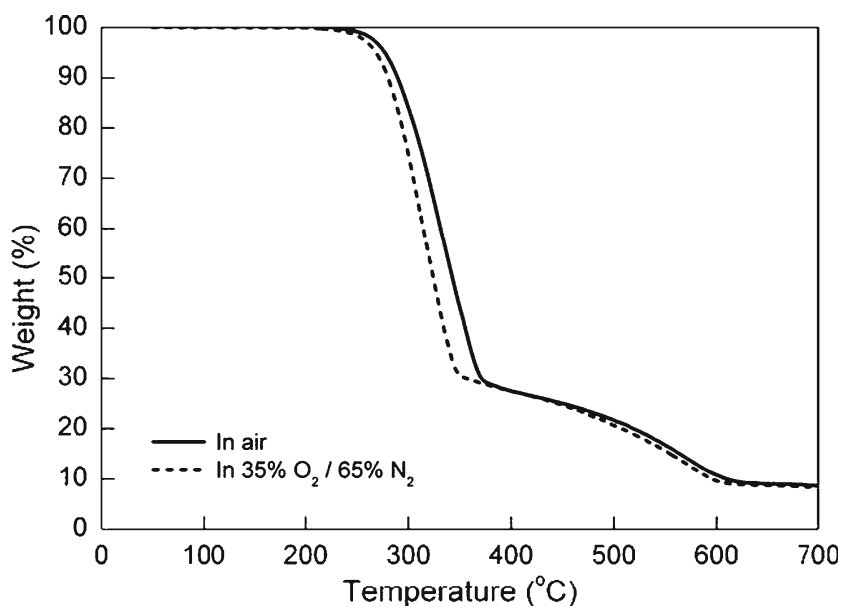

Fig. 3 Thermogravimetric analysis (TGA) of the polyurethane foam at a heating rate of $20^{\circ} \mathrm{C} / \mathrm{min}$

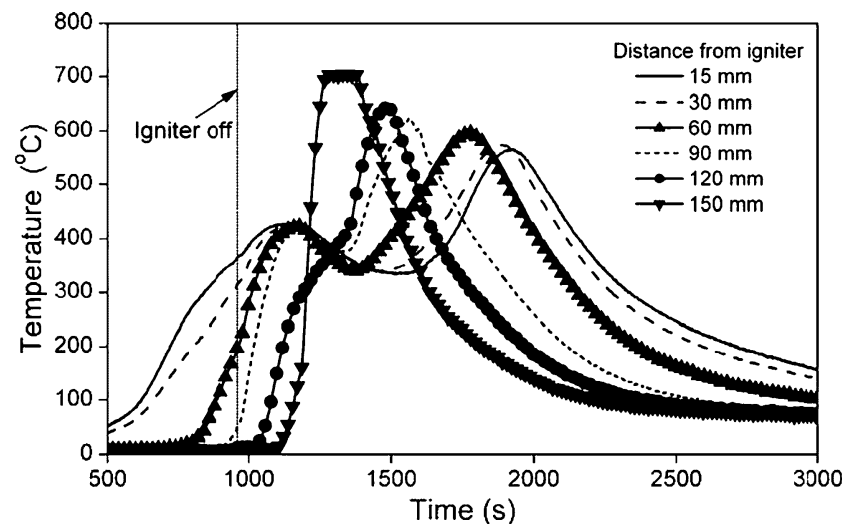

Fig. 4 Temperature histories at several locations along the foam sample for opposed flow smolder

upon the heat transferred from the opposed smoldering, which can heat up the forward smoldering foam. Thus, the behavior of forward smoldering can only be interpreted by considering the preceding opposed smoldering process.

Opposed Flow Smolder

Temperature histories along the foam centerline are shown in Fig. 4. From these data, two domains with different characteristics are identified during the evolution of the opposed smolder with time. The initial stage in the temperature history (up to approximately $1,300 \mathrm{~s}$ ) elucidates a domain of upstream-propagating smolder along with a transition to flaming at the end of foam sample. Once the opposed smolder reaction reaches the foam end and the transition to flaming takes place, a domain of forward-propagating secondary reaction prevails.

To describe the characteristics of the first domain, the analysis of data is done by dividing the foam sample in three zones. An initial zone near the igniter is approximately $60 \mathrm{~mm}$ in length, where the smoldering is affected by the ignition process. A second zone covers the central $60 \mathrm{~mm}$ of the sample where the smoldering is relatively free from end effects. A third zone is at the end of the sample where the smoldering is affected by the external environment. From Fig. 4, it is seen that temperatures in the igniter influenced zone (first two thermocouples) undergo further increase after the igniter power is switched off. This marks the beginning of a self-sustained reaction. In the middle of foam sample, a more representative opposed smoldering combustion is observed since it occurs under self-propagating conditions and is free from external effects. However, for the present experimental conditions, the maximum smolder temperature for polyurethane foam is of the order of $425^{\circ} \mathrm{C}$ in this region, almost equal to that in the igniter zone. As the smolder reaction approaches the foam end, a new scenario takes place, as indicating by the last two thermocouples. 
A localized, very fast, high temperature rise is noticed by the last thermocouple. The maximum temperature at this location, virtually not determined by the thermocouple because of its $0-700^{\circ} \mathrm{C}$ measurement range, is too high to be the indicator of a vigorous smoldering reaction. A possible explanation is that a transition to flaming is occurring there.

The temperature histories in Fig. 4 are used to determine smolder propagation velocities for polyurethane foam. Although the arrival of smolder reaction zone is characterized by a maximum in the temperature profile, in most smoldering experiments this maximum is not sharply defined. To reduce the uncertainties, the method described by Torero et al. (1993) is employed for this purpose. The location of smolder front is defined here by the intersection of the tangent to the temperature profile at the inflexion point and a horizontal line at a temperature near the maximum $\left(400^{\circ} \mathrm{C}\right.$ in this work). The smolder velocity is then calculated from the time interval of the reaction front arrival at two consecutive thermocouples, and the known distance between thermocouples. The resulting smolder velocity data are given in Fig. 5 as a function of distance from the igniter. It is noted that smolder velocities are relatively low near the igniter, and increase as the reaction propagates away from the igniter. The velocities remain almost constant $(0.42 \mathrm{~mm} / \mathrm{s})$ in the middle of the sample. Finally, at the end of the sample, a strong increase in smolder velocity is observed. The variation of smolder velocities along the foam sample also indicates the presence of the three zones described above. It is noteworthy to mention that in the middle region of the sample (where smoldering is most representative of an opposed smolder), the measured smolder velocity is considerably higher than those obtained by Walther et al. (1999) and Bar-Ilan et al. (2002) in MG smoldering experiments with air as oxidizer, while the smolder temperature is of the same order of

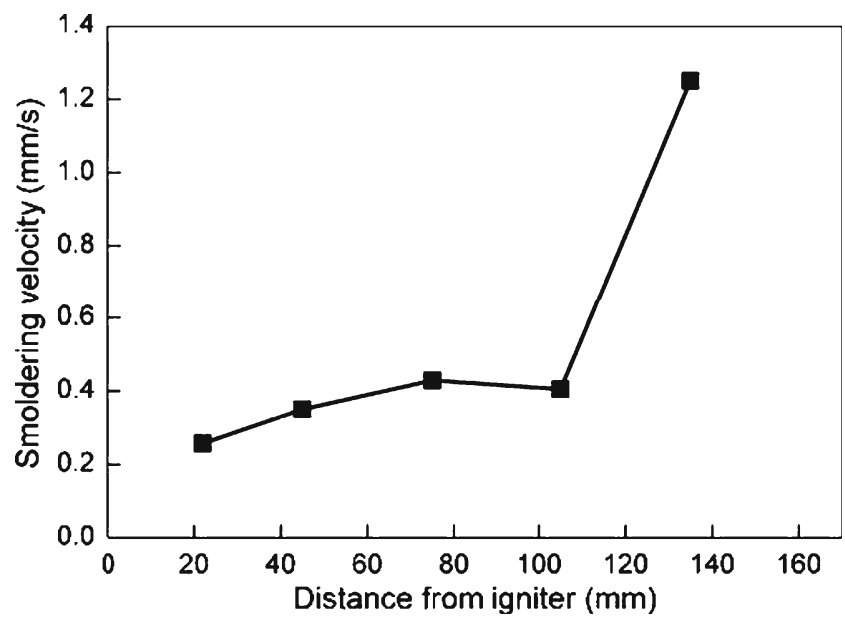

Fig. 5 Variation of the opposed smolder velocity along the foam sample magnitude to those reported by these authors. This observation indicates that the increased oxygen concentration has small effect on chemical kinetics of the smolder reaction, but results in a much higher reaction rate since an oxidizer flow with high oxygen concentration relieves the oxygen starvation in smoldering combustion.

The transition from smoldering to flaming involves a gas-phase ignition process in which the heterogeneous smolder reaction serves as a source of both fuel and elevated temperature (Torero and Fernandez-Pello 1995; Tse et al. 1996; Chao and Wang 2001). To date it has been considered to be only characteristic of forward smoldering (Torero and Fernandez-Pello 1995; Leach et al. 2000). However, in all of the studies on opposed smolder propagation, air was used as oxidizer. The effect of oxygen concentration on the smolder process has not been investigated. Ortiz-Molina et al. (1978) studied the relative smoldering tendency of polyurethane foams in a horizontal natural convection configuration by varying the ambient oxygen concentration. Although his work aimed at threshold conditions at which transition to extinguishment occurs, a few experiments with high oxygen concentrations displayed transition to flaming. The transition to flaming requires both a flammable gas mixture and a sufficient heat source for the mixture ignition. In MG, the reduced heat loss caused by the absence of natural convection can support the formation of a local high temperature region. For flow conditions in this MG experiment, oxidizer can be sufficiently transported to the opposed flow smoldering reaction zone, and the acceleration of this smolder reaction is clearly observed. Thus, when the reaction front approaches the end of the foam, enough heat flux and combustible gases can be produced, which, in conjunction with the ever available oxygen, lead to the onset of a gasphase ignition. Such a transition mechanism appears to be different from that for a forward smolder (Torero and Fernandez-Pello 1995).

Transition to flaming at the foam end terminates the first domain of the reaction and also initiates the second domain, which is characterized primarily by a forward-propagating char oxidation wave with higher temperatures than the smolder reaction. In the smoldering of polyurethane foam, a char-like material is left behind the reaction front. Although somewhat more resistant to oxidation, once reacted, the char is more exothermic than the original foam (Ohlemiller 1986; Tse et al. 1996; Chao and Wang 2001; Ohlemiller and Lucca 1983). As indicated by the thermocouple histories in Fig. 4, secondary char oxidation is triggered by the high temperature flaming combustion at the end of the foam and propagates downstream through the sample. Its presence is shown by rapid temperature increase followed immediately by temperature decrease. The temperature decrease marks the ending of the char oxidation 
reaction, and is caused by the cooling effects of incoming fresh oxidizer. Figure 6 illustrates the variation of maximum char reaction temperature as the reaction front moves toward the igniter. Although this temperature decreases linearly from $\sim 650^{\circ} \mathrm{C}$ to $\sim 570^{\circ} \mathrm{C}$ along the foam sample, it is remarkably higher than the smolder temperature. The secondary char oxidation comes to an end at approximately $1,950 \mathrm{~s}$ after most of the remaining char has been consumed.

\section{Forward Flow Smolder}

The temperature records of the other six thermocouples are presented in Fig. 7, illustrating the characteristics of the forward flow smolder. It is also helpful to discriminate between two domains of the smolder evolution. The first domain lasts up to approximately $1,950 \mathrm{~s}$, i.e. until the reaction in the upstream sample is practically completed. In this domain, the foam sample is in an ambience that is determined primarily by post-combustion gases of the preceding opposed smolder. Since smoldering is an oxygen limited process, the post-combustion gases will be depleted of oxygen. As can be concluded, in the igniter influenced region (first two thermocouples), foam temperature is brought to a level (of the order of $350^{\circ} \mathrm{C}$ ) high enough to initiate smoldering combustion. Oxidizer depletion by the opposed smoldering reaction, however, prevents an exothermic oxidation reaction from being established in the foam. The reaction will then follow an alternative pathway of endothermic pyrolysis (Tse et al. 1996; Ohlemiller and Lucca 1983). In case of pyrolysis, the oxygen concentration has to be low and heat must be available. These two conditions are reached simultaneously in the present foam region. In the other part of the foam sample (next four thermocouples), temperatures are so low that no significant chemical reaction can be expected. As a consequence, the

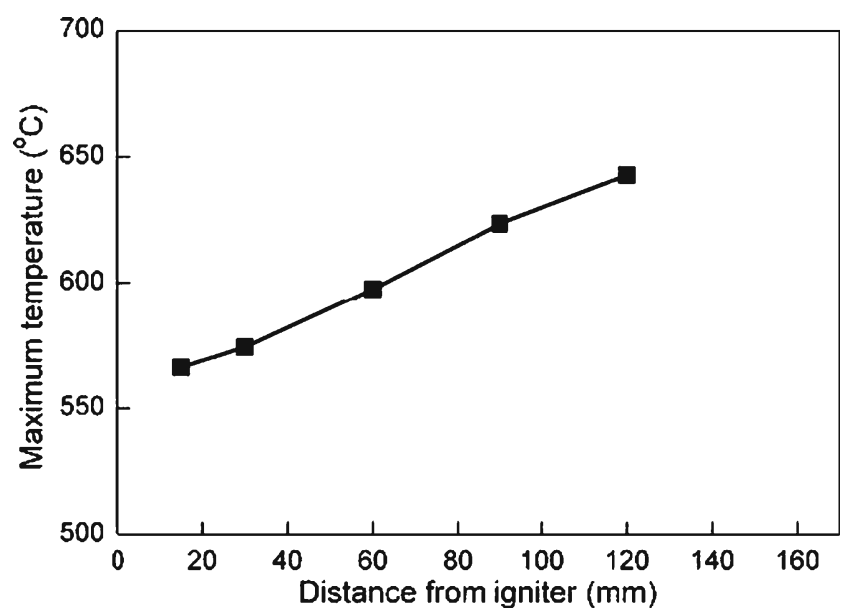

Fig. 6 Variation of the maximum char oxidation reaction temperature along the foam sample

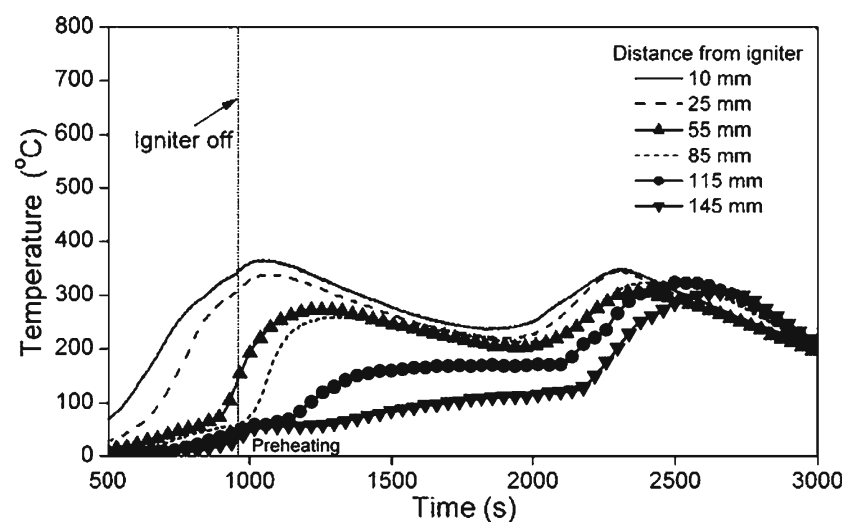

Fig. 7 Temperature histories at several locations along the foam sample for forward flow smolder

behavior of temperature profiles is controlled by the transport of heat to and from the thermocouple locations. The heat transfer inside the porous material is accomplished by conduction, radiation and also convection. The convective preheating of virgin foam by the hot post-combustion gases is observable in the temperature profiles of these four thermocouples. It is displayed by temperature plateaus at almost constant level of approximately $60^{\circ} \mathrm{C}$. Compared with the smolder temperature, this preheat temperature is much lower, indicating that the convective heating effect is relatively small. The fuel temperature changes from $\sim 242^{\circ} \mathrm{C}$ at the first thermocouple to $\sim 115^{\circ} \mathrm{C}$ at the last thermocouple when the first domain comes to its end, and characteristics of the fuel change from pyrolyzed foam in the igniter region to raised temperature, but un-reacted foam toward the sample end.

Once the reaction in the upstream foam sample finishes, fresh oxidizer flows into the downstream sample and a domain of self-sustained forward flow smolder takes place. The smolder reaction starts in the igniter region of the sample and propagates along the entire sample length. The maximum smolder temperature, ranging from $347^{\circ} \mathrm{C}$ to $305^{\circ} \mathrm{C}$, is notably lower than that measured in opposed flow (i.e. $425^{\circ} \mathrm{C}$ ). This characteristic temperature is also lower than those reported by Bar-Ilan et al. (2004) for forward smoldering of polyurethane foam in $\mathrm{MG}$ and by Torero and Fernandez-Pello (1996) in normal gravity. However, it is difficult to compare quantitatively the actual values because of the different test conditions.

A vigorous secondary char oxidation reaction is observed in the opposed smolder configuration. In contrast, this type of reaction do not appear in the forward smoldering process, even though the second domain takes place and the oxidizer flows through the char prior to reaching the smolder reaction. An explanation for this difference is that char oxidation requires both enough oxygen and also a sufficient heat source for its initiation. The TGA data in Fig. 3 show that char oxidation occurs at 
higher temperatures than smolder reaction, and the maximum reaction rate temperature is $\sim 570^{\circ} \mathrm{C}$. In the opposed smolder, when the transition to flaming is triggered near the foam end, these are two conditions (enough oxygen and high temperature) that can be encountered. In the second domain of the forward smoldering, although enough oxygen is present in the char, the char is too cold for oxidation reaction to occur.

\section{Conclusions}

This experimental study was carried out to provide a better understanding of smoldering combustion, which in turn will help to prevent and control smolder-initiated fires both in normal gravity and in spacecraft. The MG experiment was conducted with flexible polyurethane foam as fuel and $35 \% \mathrm{O}_{2} / 65 \% \mathrm{~N}_{2}$ by volume as oxidizer. It is unique in that a combination of opposed and forward flow smolder has been investigated at constant ambient pressure.

Firstly, in opposed flow smolder, a domain of selfpropagating smoldering reaction appeared. In the middle of the sample, typical smolder parameters can be achieved, including smolder velocity $(0.42 \mathrm{~mm} / \mathrm{s})$ and maximum smolder temperature $\left(425^{\circ} \mathrm{C}\right)$. Particularly important is the observation that in opposed smolder there is a transition from smoldering to flaming, which seems to be caused by the strong acceleration of the smoldering reaction. Although this transition takes place near the sample end and is a localized phenomenon, it initiates a vigorous forwardpropagating oxidation reaction in the char left behind by the smoldering reaction. The secondary char oxidation reaction is characterized by much higher temperature than the smoldering reaction. It propagates through the sample and consumes most of the remaining char.

In forward flow smolder, oxidizer depletion by the opposed smoldering reaction prevents an exothermic oxidation reaction from being established until this upstream reaction is completed. Once fresh oxidizer flows in the sample, however, the existing conditions are good enough for a self-sustained forward smoldering reaction to take place. The maximum temperature of forward smolder is notably lower than that measured in opposed flow.

The study provides additional information of practical interest in fire safety. At the same time, the data obtained in MG experiment can be used for the verification and development of smolder theory.

Acknowledgement The study reported here was sponsored by the Knowledge Innovation Major Project of Chinese Academy of
Sciences under grant number KACX2-SW-02-02. The authors would like to acknowledge the support of Chinese Academy of Space Technology that made this space experiment successful. Special thanks are due to our colleagues for their work and help during the development of this study.

\section{References}

Bar-Ilan, A., Anthenien, R.A., Walther, D.C., Fernandez-Pello, A.C., Urban, D.L.: Microgravity smoldering combustion experiments in the space shuttle. AIAA Paper 2002-1077 (2002)

Bar-Ilan, A., Rein, G., Fernandez-Pello, A.C., Torero, J.L., Urban, D. L.: Forced forward smoldering experiments in microgravity. Exp. Therm. Fluid Sci. 28, 743 (2004)

Cantwell, E.R., Fernandez-Pello, A.C.: Smoldering combustion under low gravity conditions. AIAA Paper 90-0648 (1990)

Chao, C.Y.H., Wang, J.H.: Transition from smoldering to faming combustion of horizontal oriented flexible polyurethane foam with natural convection. Combust. Flame 127, 2252 (2001)

Drysdale, D.: An Introduction to Fire Dynamics. Wiley, Chichester, England (1999)

Friedman, R.: Risks and issues in fire safety on the space station. NASA TM 198906403 (1994)

Leach, S.V., Rein, G., Ellzey, J.L., Ezekoye, A., Torero, J.L.: Kinetic and fuel property effects on forward smoldering combustion. Combust. Flame 120, 346 (2000)

Ohlemiller, T.J.: Modeling of smoldering combustion propagation. Prog. Energy Combust. Sci. 11, 277 (1986)

Ohlemiller, T.J., Lucca, T.A.: An experimental comparison of forward and reverse smoldering combustion. Combust. Flame 54, 131 (1983)

Ortiz-Molina, M.G., Toong, T.Y., Moussa, N.A., Tesoro, G.C.: Smoldering combustion of flexible polyurethane foams and its transition to flaming or extinguishment. Seventeenth Symposium (International) on Combustion, The Combustion Institute, p. 1191 (1978)

Ross, H.D.: Microgravity combustion: fire in free fall. Academic, San Diego (2001)

Stocker, D.P., Olson, S.L., Urban, D.L. Torero, J.L., Walther, D.C., Fernandez-Pello, A.C.: Small-scale smoldering combustion experiments in microgravity. Twenty-Sixth Symposium (International) on Combustion, The Combustion Institute, p. 1361 (1996)

Torero, J.L., Fernandez-Pello, A.C.: Natural convection smolder of polyurethane foam, upward propagation. Fire Saf. J. 24, 35 (1995)

Torero, J.L., Fernandez-Pello, A.C.: Forward smolder of polyurethane foam in a forced air flow. Combust. Flame 106, 89 (1996)

Torero, J.L., Fernandez-Pello, A.C., Kitano, M.: Opposed forced flow smoldering of polyurethane foam. Combust. Sci. Technol. 91, 95 (1993)

Torero, J.L., Fernandez-Pello, A.C., Urban, D.L.: Experimental observation of the effect of gravity changes on smoldering combustion. AIAA J. 32, 991 (1994)

Tse, S.D., Fernandez-Pello, A.C., Miyasaka, K.: Controlling mechanisms in the transition from smoldering to flaming of flexible polyurethane foam. Twenty-Sixth Symposium (International) on Combustion, The Combustion Institute, p. 1505 (1996)

Walther, D.C., Fernandez-Pello, A.C., Urban, D.L.: Space shuttle based microgravity smoldering combustion experiments. Combust. Flame 116, 398 (1999) 